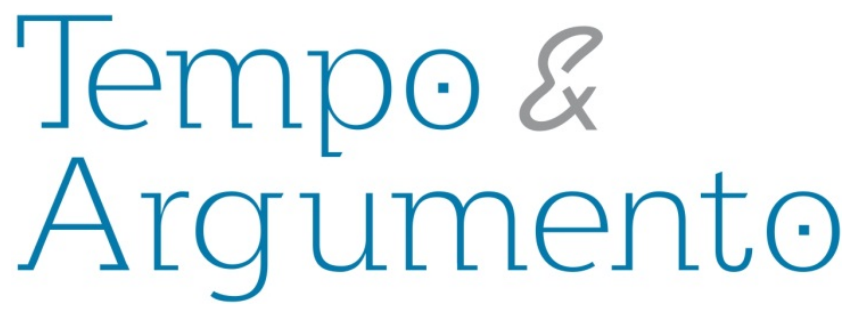

\title{
História do Tempo Presente e América Latina: Colômbia - uma entrevista com Hugo Antonio Fazio Vengoa
}

\begin{abstract}
Entrevistado
Hugo Antonio Fazio Vengoa é historiador e doutor em ciência política, professor da Universidad de los Andes (Bogotá - Colômbia) desde a década de 1990, onde desenvolveu e coordenou diversas atividades, incluindo a criação dos programas de mestrado e doutorado em História. Atualmente é decano da Faculdade de Ciências Sociais. Suas investigações estão focadas em temas como a História Global, Estudos Internacionais Contemporâneos $e$ História do Tempo Presente. No decorrer de sua carreira acadêmica publicou mais de vinte livros, dentre esses merece destaque o livro intitulado "La historia del tiempo presente: historiografía, problemas y métodos" (2010). Membro do Grupo de Investigação Historia del Tiempo Presente.
\end{abstract}

\section{Entrevistadora}

\author{
Elisangela da Silva Machieski \\ Doutoranda no Programa de Pós- \\ Graduação em História da Universidade \\ do Estado de Santa Catarina. \\ Brasil \\ lismachieski@gmail.com \\ Revisão

\section{Gabriel Tolosa Chacón} \\ Doutorando no Programa de Pós- \\ Graduação em Educação da \\ Universidade Federal de Santa Catarina. \\ Brasil \\ gatolosa@openmailbox.org
}

Entrevista concedida em abril de 2017.

\section{Para citar esta entrevista:}

FAZIO VENGOA, Hugo Antonio. História do Tempo Presente e América Latina: Colômbia - uma entrevista com Hugo Antonio Fazio Vengoa. [Entrevista realizada em xx de abril, 2017]. Revista Tempo e Argumento, Florianópolis, v. 9, n. 20, p. 344 - 457, jan./abr. 2017. Entrevistadora: Elisangela da Silva Machieski. 
Tempo e Argumento: ¿Cuál fue su trayectoria académica desde el inicio de sus estudios universitarios?

Hugo Fazio Vengoa: Mi trayectoria académica y mi interés por los temas del presente son indisociables de mi propia experiencia personal. Luego del golpe de Estado en Chile, el fatídico 11 de septiembre de 1973, tuve que salir intempestivamente del país e inicié, de esa manera, un largo y enriquecedor recorrido por diversos países socialistas europeos. Tuve la fortuna, más aún siendo un historiador que siente especial predilección por el estudio de los temas del presente, de vivir en Berlín, capital en ese entonces de la hoy inexistente República Democrática Alemana; posteriormente en Praga, la bella y siempre recordada capital de la también difunta Checoslovaquia; y finalmente en Moscú, capital de la Unión Soviética, la superpotencia también desaparecida. Los ocho años que residí en esos países no sólo me familiarizaron con sus idiomas, historias y culturas, sino que además con un conocimiento de primera mano de lo que era el "socialismo real".

Esta experiencia selló mi interés por estudiar y comprender los países del “socialismo real”. En ese entonces, esta escogencia temática obedecía a profundas convicciones. Se motivaba en el interés geoestratégico que representaban estos países y principalmente la Unión Soviética en el escenario internacional, la importancia que sus epígonos o detractores le asignaban a esta particular experiencia histórica, el atractivo que en mí despertaba el estudio de formas de modernización diferentes a la occidental y esa aureola de misterio que irradia la sociedad rusa a través de su enigmática e imponente cultura. Esta indescriptible sensación la expresó de manera elegante el antiguo Primer Ministro británico, Winston Churchill, cuando la definió como "un acertijo envuelto en un halo de misterio dentro de un enigma". 
Tempo e Argumento: ¿Cómo fueron sus comienzos en la docencia universitaria?

Hugo Fazio Vengoa: Luego de esta prolongada estadía en el Viejo Continente me vine a Bogotá donde viví por cuatro años y realicé un Magister en Historia en la Universidad Nacional de Colombia. Por la misma época, comencé mis primeras actividades docentes en varias universidades bogotanas y publiqué mis primeros artículos sobre la coyuntura y la historia de la Unión Soviética.

Corría el año de 1987 y la situación política en Colombia se deterioraba de día en día. Se asistía a asesinatos sistemáticos de dirigentes y militantes de la Unión Patriótica ${ }^{1}$. Y en ese río revuelto de la desquiciada violencia, yo -que no tenía ninguna filiación partidaria ni la menor intención de tomar partido por alguna de las opciones políticas colombianas porque mis preocupaciones e intereses eran de naturaleza exclusivamente académica, pero trabajaba sobre un tema que permitía que algunos me asociaran con determinadas posiciones políticas- quedé envuelto en medio de la vorágine. Las amenazas comenzaron a llegar de diferentes lados: para unos, me encontraba realizando proselitismo político entre los hijos de la "elite" a través de la cátedra universitaria, mientras que para otros mis publicaciones constituían una traición a los "genuinos" ideales del socialismo. En conclusión, como muchos colombianos tuve que abandonar con mi familia intempestivamente el país y, después de una travesía por varios países europeos, aterricé en la Universidad Católica de Lovaina, institución que me abrió sus puertas para realizar un Doctorado en Ciencia Política en el área de relaciones internacionales.

\footnotetext{
${ }^{1}$ La Unión Patriótica (UP) fue un partido político de izquierdas nacido en 1985 , en el marco de las negociaciones de paz entre el gobierno colombiano y varios grupos guerrilleros. Más adelante se distanció de la lucha armada y abogó por la solución pacífica al conflicto colombiano, tras la incorporación de integrantes del Partido Comunista y otros sectores. Entre los años 1986 y 1994, los militantes de la UP fueron víctimas un exterminio sistemático, implementado por parte del establecimiento colombiano, en vinculación con grupos de narcotraficantes y paramilitares. Alrededor de 4000 miembros de la UP fueron asesinados, entre los cuales se incluyen dos candidatos presidenciales, ocho senadores, trece diputados, setenta concejales y once alcaldes. Varios analistas calificaron la tragedia del mencionado partido como un genocidio político. En el año 2012, el presidente Juan Manuel Santos reconoció la responsabilidad del Estado colombiano en el exterminio de la agrupación [NdoR].
} 
Tempo e Argumento: ¿Cuál fue el tema de su investigación de doctorado?

Hugo Fazio Vengoa: Como llevaba varios años dedicado a los estudios soviéticos, propuse como tema para mi investigación doctoral el lugar de América Latina en la política internacional de la Unión Soviética. La propuesta fue del agrado de la comisión doctoral. Claro que no puedo dejar de comentar la sorpresa que en los miembros de la mencionada comisión despertaba el hecho de que un chileno, con pasaporte italiano, venido de Colombia, se propusiera investigar sobre el coloso euroasiático, tema que, por lo general, estaba reservado a los investigadores de las naciones industrializadas.

Los tres años que permanecí en Bélgica fueron un intenso período en el que pude concentrarme de tiempo completo en los estudios soviéticos. Me beneficié del clima gorbachoviano entonces existente, de la calidad de las publicaciones que en esos años vieron la luz, de la intensidad y la sofisticación de los debates sobre el “socialismo real" y sus experiencias históricas y de un acceso casi ilimitado a información de primera mano. Al finalizar el programa de estudios, el destino -una vez más el sempiterno azar- me trajo de nuevo a Colombia, donde he tenido la oportunidad de proseguir con mis actividades académicas e intelectuales, siendo Rusia, uno de los temas más recurrentes.

Tempo e Argumento: ¿Cómo fue su regreso a Colombia después de esa estadía en Europa?

Hugo Fazio Vengoa: En 1990 fui contratado por la Universidad de los Andes como profesor de tiempo completo y mis actividades se desarrollaron en dos direcciones: la docencia sobre temas internacionales contemporáneos y la investigación sobre temas de actualidad. Ocurre que cuando vuelvo la vista atrás, rememoro los asuntos que han concitado mi atención y evoco los principales ejes temáticos de mis estudios y de la práctica investigativa, me llama poderosamente la atención que siempre he tenido una predilección muy marcada por temas propios de un planeta del tamaño de Júpiter; mi interés académico siempre se ha sentido atraído por las cuestiones enormes. $\mathrm{Y}$ es que, cuando he tenido que tratar temas de dimensiones 
gigantescas, me he sentido a mis anchas, las ideas fluyen a mi mente, los problemas los entiendo de manera fácil, mientras que cuando he intentado trabajar en torno a tópicos pequeños y específicos, reconozco que salen a relucir todas mis impericias.

En los noventa, con la preocupación de encontrar nuevos puntos de referencia teóricos e históricos y nuevos asideros intelectuales, emprendí un gran cambio en mi orientación temática y me dediqué al estudio de aquel esquema mundial que se iba configurando, es decir, me interesé por la comprensión de las coordenadas básicas del ordenamiento internacional que estaba emergiendo en las postrimerías del siglo XX.

Tempo e Argumento: ¿Su experiencia fuera de Colombia influyó en sus investigaciones?

Hugo Fazio Vengoa: Fueron esos los años en los que, sin proponérmelo de modo consciente, comencé a reflexionar sobre el mundo en su conjunto. En el recodo del último cambio de siglo, mi atención se centró en la globalización, tema que escudriñé desde distintos ángulos, latitudes y niveles de observación. El estudio del nuevo ordenamiento mundial, de la globalización, y mis divergencias con las formas habituales de aproximación a los temas mundiales me condujeron a interesarme por la historia global de la contemporaneidad, trama mucho más extensa que la historia de la globalización, pues considero que esta última no es más que uno de sus posibles desarrollos.

Paralelamente comencé a preocuparme por las distintas maneras a través de las cuales puede ser estudiada la contemporaneidad o, lo que, con agrado, he definido como la historia del tiempo presente. Hace ya unos buenos años, me he sentido más identificado con el rótulo que le dio cierta historiografía francesa, surgida a finales de los años setenta del siglo pasado, aunque difiera de modo sustancial en cuanto a su contenido. Las razones que me han llevado a preferir este título y no otro, así como el sentido específico que le asigno a esta expresión y a su temporalidad, porque considero que la fascinación por el estudio histórico actual sobre el presente constituye una demostración palmaria de que el mundo de ahora se encuentra 
frente a lo que podría denominarse como una experimentación moderna y contemporánea de la historicidad, cuyo centro nodal se sitúa en una pluralización de los registros espacio-temporales y que, dentro de estas coordenadas, el presente interviene como un puente que enlaza a todos ellos.

Ambos temas -la historia del tiempo presente y la historización del mundo que nos ha correspondido vivir, con su correspondiente genealogía- han sido un par de preocupaciones intelectuales que me han servido de compañeros de ruta por varias décadas. La primera vez que en mí afloró esta inquietud intelectual ocurrió de manera bastante indirecta. Trabajando sobre la transición en los países de la Europa Centro Oriental, me sorprendió la frivolidad con la cual los politólogos, sociólogos, economistas, etc., analizaban el fin del comunismo y el establecimiento de la nueva sociedad.

Una tesis que gozaba de gran unanimidad arrancaba del supuesto de que el proceso era el mismo por doquier, razón por la cual se presuponía que las mismas recetas tenían que producir idénticos resultados. Sin embargo, una observación rápida, pero fundamentada en un conocimiento histórico, demostraba que el Estado de derecho, la economía de mercado, la privatización o cualquier otra política con carácter global que se aplicara en estos países, producía resultados muy distintos en cada una de estas naciones.

El entendimiento de este problema me llevó a desarrollar una aproximación histórica que tomara en cuenta las particularidades del sistema anterior y las peculiaridades de la transición en cada caso en particular. Con base en estos lineamientos concluía en dicha oportunidad, que cuando el problema era visualizado desde este ángulo se podía comprender con facilidad porque en algunas experiencias la reorganización social se realizaba a través de un descentralizado mercado (la República Checa), en otras el eje central gravitaba en torno al Estado (Hungría), etc., e incluso esta perspectiva permitía comprender por qué algunos Estados experimentaban transiciones pacíficas, mientras otros explotaban y se desangraban, tal como ocurrió con Yugoslavia y la Unión Soviética. 
Tempo e Argumento: ¿Cómo llegó usted a ese interés por la Historia del Tiempo Presente?

Hugo Fazio Vengoa: En mi interés por identificar los elementos centrales de esta propuesta de lectura histórica del presente publiqué en la revista Historia Crítica un artículo que llevaba por título "La historia del tiempo presente: una historia en construcción”2. Esa fue la primera vez que intenté exponer de manera más o menos sistemática algunas ideas, vagas todavía, diría hoy, sobre el significado que comportaba esta historia. Por esos mismos años, inauguré una cátedra en el curso de graduación en Historia de la Universidad de los Andes que portaba el mismo encabezado y ofrecía un vistazo histórico a un buen número de asuntos contemporáneos de alto interés para el público estudiantil. Después, esta práctica docente fue presentada para los programas de posgrados de la Facultad de Ciencias Sociales de la mencionada Universidad. Paralelamente, con un grupo de colegas en el Departamento de Historia nos pusimos en la tarea de crear un grupo de investigación sobre la historia del tiempo presente, y ese semillero de reflexión e investigación perdura hasta el día de hoy. Con estos apoyos académicos e institucionales, las ideas que a continuación se exponen sobre el presente pudieron seguirse desarrollando.

En investigaciones posteriores que tuve la fortuna de realizar sobre temas de la actualidad internacional me vi en la necesidad de volver recurrentemente sobre algunos de los elementos de esta historia. Tal como fue expuesto anteriormente, este interés por seguir trabajando en la historia del tiempo presente se alimentaba de la preocupación por acometer investigaciones no desde la perspectiva habitual la politología o de las relaciones internacionales, sino con base en un entendimiento histórico, debido al convencimiento de que la falta de historicidad del presente, de la cual los historiadores seguramente eran sus principales responsables, se había alzado en uno de los principales escollos que entorpecían la comprensión de los fenómenos que se desarrollan delante de nosotros. Así ocurrió, por ejemplo, cuando trabajé sobre ciertos acontecimientos contemporáneos que me enfrentaron

\footnotetext{
2 FAZIO VENGOA, H. La historia del tiempo presente: una historia en construcción. Historia Crítica, n. 17, p. 47-57, 1998. Disponível em: http://www.redalyc.org/articulo.oa?id=81111329004.
} 
con la tarea de tener que reflexionar sobre el significado de estas situaciones para la comprensión de la contemporaneidad, o cuando quise definir los contornos temporales del presente que nos ha correspondido vivir o precisar los caracteres fundamentales del mundo contemporáneo.

El valor que encierra el estudio histórico del presente para la disciplina en su conjunto obedece a que esta vertiente de la historia se ha convertido en uno de los campos más dinámicos e innovadores en la materia, puesto que ha tenido que producir una reflexión madura, particularmente en lo que respecta a la renovación en la producción de las fuentes e imágenes, en el entendimiento del lugar del tiempo y del espacio en la historia, además de ser una perspectiva que ha ensanchado el campo disciplinar a nuevas temáticas y preocupaciones sociales. También es un área cuyo conocimiento es fundamental porque la comprensión de su contenido lleva a replantear muchos de los supuestos básicos en los cuales ha descansado habitualmente la disciplina, además del hecho de contener interesantes indicaciones sobre cómo llevar a cabo la interpenetración o, mejor dicho, la compenetración entre la historia y las demás ciencias sociales.

Otra preocupación intelectual que me estimulado en la dirección de historizar el presente puede ser resumida en los siguiente términos: no me cansaré de insistir en la sorprendente dificultad que experimentan muchos analistas especializados en los temas contemporáneos - sociólogos, politólogos, economistas, comunicadores, historiadores, expertos en relaciones internacionales, etc.- cuando tratan de exponer y explicar las coordenadas fundamentales de la contemporaneidad que nos ha correspondido vivir e incluso cuando tienen que analizar un problema específico en particular.

Es tal la desazón y tantas las dificultades que continuamente experimentan que se ha vuelto un lugar común toparse con expresiones tales como "el nuevo desorden mundial" o con la insinuación de que se viven tiempos borrascosos, tormentosos, indescifrables o simplemente inasibles. Otros no se cansan en buscar en muchos acontecimientos actuales el inicio de una "nueva época”, aun cuando siempre sean 
bastante endebles las bases sobre las que se pretende construir dichos supuestos. Esta tesis se pregonó hasta la saciedad cuando sobrevinieron los ataques a las Torres Gemelas y al edificio del Pentágono en septiembre de 2001. Sin embargo, los años pasan, la historia profunda sigue su inminente cauce y se observa que las fosforescencias de estos eventos comenzaron a extinguirse tempranamente.

El problema de fondo pareciera consistir en que -desde el momento en que se desvanecieron los rígidos guiones que gobernaban la época de la guerra fría, los cuales eran fáciles de comprender y permitían además validar los respectivos puntos de vista en referentes "seguros", sencillos y precisos- la vida internacional se encontrara navegando sin rumbo o hubiera quedado "privada de sentido"

En este sentido, considero que -si se ofrecen algunas herramientas conceptuales y analíticas que permitan convertir a la historia en una propuesta de interpretación y de explicación de la contemporaneidad- un procedimiento tal puede servir para corregir este exceso de confusión que reina en la actualidad, permite atacar la superficialidad argumentativa, hace posible mirar al futuro con optimismo y, más importante aún, desbloquea las compuertas del presente para su posible historización. A mi modo de ver, esto último reviste la mayor importancia porque si la vida internacional contemporánea es imaginada como "sin sentido" o "borrascosa" no es porque lo sea, sino porque es tan bajo el nivel de historización del presente que no ha podido decodificarse como un proceso ni han podido identificarse sus rasgos más inmanentes.

\section{Tempo e Argumento: En la actualidad, ¿cuál es su línea de investigación?}

Hugo Fazio Vengoa: En cuanto a mi actual línea de trabajo investigativo ésta se orienta a determinar los caracteres fundamentales de la contemporaneidad, lo cual explicaré de la siguiente manera: en la literatura científica -y también en aquella destinada al gran público- es habitual encontrar indicaciones, aserciones o simples declaraciones que insinúan que las sociedades contemporáneas, en estas décadas iniciales del siglo XXI, han adquirido fisonomías originales, diametralmente distintas de las de 
cualquier periodo previo. Afirmaciones de este tipo se han vuelto tan corrientes y constituyen, muchas veces, generalizaciones tan triviales, que los estudiosos de la contemporaneidad prefieren pasarlas por alto y no es común que se apasionen y se trencen en polémicas con ellas. Esta relativa indiferencia seguramente explica por qué los enunciados rara vez logran convertirse en argumentos que susciten algún tipo de debate o que desaten una acalorada discusión intelectual. Tampoco se requiere ser un experto calificado para conjeturar que toda generación, durante la época moderna, ha considerado que su presente constituye un momento incomparable, excepcional, inconfundible, único en la historia, y que su época se singulariza por una serie de situaciones y hechos fácilmente identificables, que son completamente novedosos en relación con otros períodos de la historia pasada, incluidos algunos relativamente próximos.

Debo admitir que la tesis del carácter excepcional del presente contemporáneo no ha constituido una afirmación o una insinuación baladí. Desde hace ya un buen número de años he venido considerando que existen sólidos fundamentos que le dan apoyo a la idea de que la contemporaneidad que nos ha correspondido vivir es sustancialmente distinta de las anteriores, que representa un intervalo de tiempo que comporta una serie de dinámicas y situaciones muy específicas y que el espesor de las transformaciones es tan impresionante que éstas no pueden ser provisorias.

El convencimiento de esta singularidad de época me ha llevado a preguntarme si es correcto que las incertidumbres intelectuales sigan gravitando en torno a la originalidad de la contemporaneidad, asunto que resulta incontrovertible cuando simplemente se contemplan los adelantos científicos y tecnológicos que modifican la vida de millones de personas en el planeta, o si debería avanzarse más bien en reflexiones que acaricien la idea de que nos encontramos en los albores de una era mundial completamente nueva.

Un importante imperativo del porqué la relación entre la inmediatez y un ayer necesita ser recompuesta radica en que es fuerte la tendencia en las sociedades contemporáneas a deshistorizar el presente, a considerar que el pasado "existe" de 
manera instrumental, solo en razón de ciertos intereses actuales. Que el presente sea desvinculado del pasado, de por sí, constituye un problema inmenso, pero el asunto mayor radica en que cuando se destemporaliza el presente se achata de manera proporcional la capacidad de entendimiento y explicación de los dilemas sociales, porque sólo logran ser apreciados en los términos de las fosforescencias que emitan, sin que ello descubra su esencia intrínseca.

La necesidad de recomponer el tejido con el pasado se convierte igualmente en un asunto político de primer orden porque mientras en épocas pasadas el acceso limitado a la información -suministrado por los sistemas de educación, los mecanismos de socialización y los medios de comunicación- generaba marcos de comprensión más o menos similares, en la actualidad, en la era de la comunicación digital y de acceso a distintas fuentes de información, se erosionan los elementos que asocian los individuos, al tiempo que se dimensionan ciertos "pasados concurrentes", como los relativos a la memoria, como si estos no fueran combates por y para el presente.

Ha sido precisamente la comprensión de este vínculo indisoluble entre el momento inmediato, es decir, la actualidad del día a día, con cierto "pasado cercano" o "pasado presente" lo que me ha llevado a argumentar que la contemporaneidad debe ser considerada un presente histórico, o sea, un espacio de tiempo con una duración variable que se ha prolongado a través de un buen número de décadas.

Esta inclusión de la actualidad inmediata dentro de un intervalo de tiempo, con una extensión que no puede ser determinada de antemano y que emana de la misma historia presente, me ha llevado a sostener que las dinámicas y las situaciones que caracterizan la coyuntura actual deben ser abordadas no como simples emanaciones del momento que se vive, sino que tienen que ser tratadas como fenómenos aprehensibles en su duración.

Con base en estas premisas he llegado al convencimiento de que cuando se pretende abordar asuntos tan trascendentales como las transformaciones que ha experimentado el Estado, el nuevo rostro del capitalismo, la financiarización de las 
economías y de las sociedades, el desfogue del mercado, la proliferación de nuevas gamas de actores sociales, la inclusión de los referentes culturales en la política, los bosquejos de intentos de construcción de un nuevo ordenamiento geoeconómico y político mundial, entre otras tantas cosas que aquí podría enumerar, el estudioso debe esmerarse por analizarlos en su proyección temporal, es decir, en términos de sus duraciones, debido a que todas estas situaciones son dinámicas o fenómenos en desarrollo que se revelan y que son amplificadas por las cambiantes condiciones temporales y espaciales del presente histórico.

Hace algunos años expuse la tesis de que fue durante la extendida década de los setenta, cuyos orígenes simbólicamente se remontan al annus mirabilis de 1968, cuando irrumpió el período histórico comprensivo de la contemporaneidad. En este sentido, la década de los setenta representó la coyuntura histórica germinal durante la cual descolló un conjunto de grandes transformaciones en todos los ámbitos sociales que afectaron de manera diferenciada, aunque de modo constante, a países de todos los continentes. Esta fase transformadora inicial constituyó un momento muy singular, inédito, porque, por vez primera en la historia humana, sus repercusiones se manifestaron en todos los pueblos del mundo; fueron cambios de gran envergadura en todos los ámbitos sociales, que no quedaron circunscritos a ninguna región geográfica en particular, aun cuando, claro está, sus modulaciones y articulaciones fueran diferenciadas en los distintos casos, esferas y latitudes.

En el hecho de que aquel momento testimonie la aparición de transformaciones con proyección mundial radica precisamente la gran novedad que encierra este intervalo de tiempo que he definido como el presente histórico contemporáneo, un presente de mundo que engloba a todas las naciones particulares.

Tempo e Argumento: ¿Cómo podría situar su producción académica dentro del escenario historiográfico de Colombia?

Hugo Fazio Vengoa: No es fácil situar mi producción académica dentro de los marcos de la historiografía colombiana, porque mis temas nunca se han relacionado con 
Colombia, en las condiciones en que la mayoría de los investigadores trabaja temas sobre el país. Mis investigaciones han girado en torno a Europa (Centro Oriental y temas referidos a la integración), la globalización, la historia del tiempo presente, la historia global, el presente histórico, etc. En sí, puedo decir que mi labor se ha encaminado en la dirección de ayudar a "desprovincializar" las ciencias sociales colombianas y, de manera indirecta, a contribuir a la toma de conciencia en la necesidad de tender puentes con "otras historias".

Tempo e Argumento: Actualmente, ¿cuáles son los enfoques de sus trabajos?

Hugo Fazio Vengoa: Desde hace algunos años he venido trabajando en el desarrollo de una propuesta histórica de comprensión del mundo contemporáneo. Este es un esfuerzo de largo aliento -que entremezcla la historia global con la historia del tiempo presente- porque pretende dar cuenta de los caracteres fundamentales de aquello que llamo el presente histórico mundial, período que arrancó a finales de la década de los sesenta y se extiende hasta hoy.

Tempo e Argumento: ¿Cómo la Historia del Tiempo Presente se volvió una preocupación en su carrera de historiador? ¿Cuáles fueron las referencias teórico-metodológicas que le influenciaron en su proyecto de historizar el "tiempo presente"?

Hugo Fazio Vengoa: Siempre me interesaron los temas del presente, pero el gran impulso para concentrarme en esta área provino de mis estudios de ciencia política y del convencimiento a que llegué sobre las grandes dificultades que experimenta la politología para dar cuenta de las dinámicas del presente. En el fondo, gracias a la ciencia política llegué al convencimiento de que para hacer inteligible la contemporaneidad se requería de una historización del presente. Por tanto, mis investigaciones constituyen un diálogo con la ciencia política y este referente me llevó a delinear los contornos de este campo de la historia. 
Tempo e Argumento: En el Brasil, durante algún tiempo, el campo de la historia del tiempo presente fue blanco de críticas, sobre todo en cuanto a los procedimientos del hacer historiográfico que implica. ¿Cómo se constituyó ese campo del saber en Colombia? ¿Cuáles son los principales temas de investigación por los historiadores del "tiempo presente" en aquel país?

Hugo Fazio Vengoa: La historia del tiempo presente, tal como la entiendo, sigue siendo un campo debatido por los historiadores, quienes se resisten a concebir la posibilidad de historizar el presente, porque muchos de los supuestos con los que trabajan no son aplicables a la actualidad. Para mí la historia del tiempo presente es más que un método o una forma de trabajo, es un enfoque que le confiere una alta importancia a las métricas de tiempo en el discernimiento de la contemporaneidad.

Tempo e Argumento: En términos historiográficos, ¿existen diferencias entre la Historia del Tiempo Presente producida en Colombia y en otros países latinoamericanos?

Hugo Fazio Vengoa: En Colombia la historia del tiempo presente está aún en su infancia, porque en general la historia aún está en su infancia. En otros países se han alcanzado logros mayores en investigaciones puntuales. No obstante, se puede pensar en un futuro promisorio porque es grande el interés entre los jóvenes y los estudiantes por el estudio del presente.

Universidade do Estado de Santa Catarina - UDESC Programa de Pós-Graduação em História - PPGH Revista Tempo e Argumento Volume 09 - Número 20 - Ano 2017 tempoeargumento@gmail.com 